Case Report

\title{
Superficial Myofibroblastoma in the Vulva Mimicking Aggressive Angiomyxoma: A Case Report and Review of the Literature
}

\author{
Wei-Xia Peng (D), ${ }^{1,2}$ Ryuichi Wada (D), ${ }^{1}$ Shoko Kure, ${ }^{1}$ \\ Masaharu Fukunaga, ${ }^{3}$ and Zenya Naito ${ }^{1}$ \\ ${ }^{1}$ Department of Integrated Diagnostic Pathology, Nippon Medical School, Japan \\ ${ }^{2}$ Department of Pathology, Misato Kenwa Hospital, Japan \\ ${ }^{3}$ Department of Pathology, Shinyurigaoka General Hospital, Japan \\ Correspondence should be addressed to Wei-Xia Peng; weixiapeng@nms.ac.jp
}

Received 1 February 2019; Revised 22 April 2019; Accepted 9 May 2019; Published 26 May 2019

Academic Editor: Stefan Pambuccian

Copyright (C) 2019 Wei-Xia Peng et al. This is an open access article distributed under the Creative Commons Attribution License, which permits unrestricted use, distribution, and reproduction in any medium, provided the original work is properly cited.

Background: Superficial myofibroblastoma (SMF) is a very rare benign mesenchymal tumor in the female lower genital tract. Only 46 cases have been reported in the English language literature, among which only 7 cases arose in the vulva. Sometimes SMF histologically mimics aggressive angiomyxoma (AA) in which massive myxoid change in stroma is characteristic. We herein report a case of vulvar SMF with prominent myxoid stroma and review the literature with the emphasis on the differential diagnosis of SMF and AA. Case presentation: a 37-year-old woman presented with a painless mass in the vulva. Magnetic resonance imaging (MRI) showed a well-circumscribed $7 \mathrm{~cm}$ mass in the subcutis of the vulva. The tumor was resected. Histopathologically, the tumor was characterized by sparsely populated spindle-shaped cells in the fibromyxoid stroma. Thin-walled blood vessels were detected. Mitoses or pleomorphism was not found. Tumor cells were positive for vimentin, ER, PgR, and desmin. Some cells were positive for alpha-SMA and CD34. All cells were negative for S100 protein. Conclusions: because SMF and AA show different clinical prognoses, distinguishing SMF from AA is important. However, SMF may share many common histological features with AA: superficial localization (above fascia), sharp borderline from adjacent tissue, expansive growth pattern; a specific vascular pattern will lead to an accurate diagnosis of SMF. Familiarization with the histological characteristics of the two entities will help to make a prognostic prediction.

\section{Background}

Superficial myofibroblastoma (SMF) is a very rare benign mesenchymal tumor of the female genital region. To date, only 46 cases have been reported in the English language literature [1-6]. Formerly, SMF was known as superficial cervicovaginal myofibroblastoma because it was believed to occur exclusively in the cervix and vagina. In 2005, Ganesan R et al. [2] proposed the term "superficial myofibroblastoma of the lower female genital tract" for this type of tumor because they found that some tumors with the same histological and immunohistochemical features also could occur in the vulva. Although some cases were reported thereafter, so far, only seven cases of SMF have been reported to arise in the vulva $[2,3,6]$. Thus, many gynecologists and pathologists might not be familiar with this type of tumor.

Histologically, SMF is characterized by myofibroblast proliferation in collagenous and myxoid stroma. The cellularity is always moderate to low. The collagen and myxoid stroma proportions may vary among cases. Blood vessels may be abundant in some cases. Sometimes, SMF may be associated with extensive edema in the stroma, which may make it difficult to distinguish it from aggressive angiomyxoma (AA). However, the clinical prognoses of the two tumors are different. Thus, familiarization with the characteristics of SMA and AA is important. 


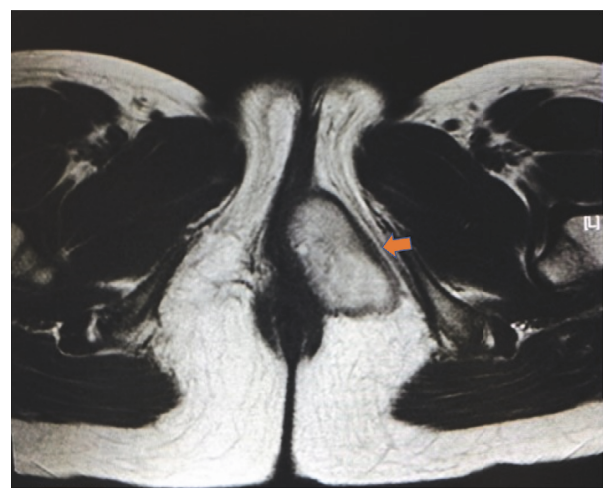

FIGURE 1: Magnetic resonance imaging of the pelvis showed a well-circumscribed mass in the vulvar subcutaneous region.

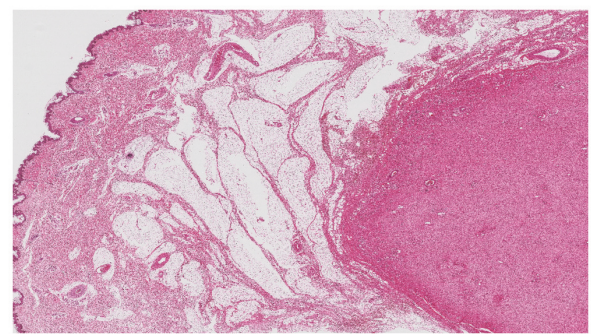

Figure 2: On histopathological examination $(\times 10 ; \mathrm{HE})$, the tumor was located in the subcutaneous region. There is an uninvolved segment between the tumor and overlying squamous epithelium. The boundary between the tumor and adjacent tissue was well demarcated.

\section{Case Presentation}

A 37-year-old woman, G1P1, was referred to our hospital due to an increase in size of a tumor in her vulva. The mass was first pointed out to her during her delivery one year earlier. The patient had no apparent symptoms. Magnetic resonance imaging (MRI) of the pelvis showed a well-circumscribed mass in the vulva (Figure 1). The patient underwent resection of the tumor, and the tumor was subjected to histological examination. There was no apparent evidence of recurrence one year after the resection.

Grossly, the tumor mass was located in the subcutis and measured $73 \times 29 \mathrm{~mm}$. There was no fibrous capsule, but the tumor was well circumscribed. The cut surface showed a yellowish-white mass with gelatinous change. No hemorrhage or necrosis was observed.

On histopathological examination (Figure 2), the boundary between tumor and adjacent tissue was clear. Tumor cells were short and spindle-shaped without prominent atypia, arranged in no overt architecture. No necrosis or mitoses were identified. The stroma was edematous and myxoid; fine collagen as well as dense collagen was detected in some regions. The vast majority of blood vessels were small-sized with thin walls. Some medium-sized blood vessels were also identified within the lesion (Figure 3). There was no specific distribution pattern of the vascularity. Immunohistochemical studies were performed using the primary antibodies listed in Table 1. On immunohistochemical analysis, most tumor cells showed positivity for vimentin, ER, PgR, and desmin. Some tumor cells showed positive for alpha-SMA and CD34. The tumor cells were uniformly negative for S100 protein (Figure 4). The Ki-67 labeling index was less than $2 \%$.

\section{Discussion and Conclusions}

Diagnosing genital mesenchymal tumors is usually challenging because they are rare, and some of them show many similar clinicopathologic features. Hypocellularity, marked edema, and myxoid change, as well as prominent blood vessel proliferation in the stroma, made the present case atypical and difficult to distinguish from AA. SMF, as well as many other genital mesenchymal tumors, may exhibit massive myxoid change in the stroma. Especially in tumors in superficial regions, edema and myxoid change due to external stimulation is a common secondary change. Therefore, a myxoid stroma is not an exclusive finding of AA. Although in rare cases, SMF may show marked proliferation of blood vessels in the stroma, the blood vessels are always small- to medium-sized. Large-size vessels with thick muscular walls or hyalinized change are seldom seen. Furthermore, the vessels have a trend to concentrate in the central region of the lesion. However, blood vessels in AA are always abundant and multifarious, varying from capillary-like to large-caliber vessels with thick muscular walls. Moreover, an arborizing vascular pattern, as seen 
TABLE 1: Primary antibodies used in this study.

\begin{tabular}{lccc}
\hline Antibody & Clone & Type & Dilution \\
\hline ER & SP1 & rm & Ready to use \\
PgR & iE2 & rm & Ready to use \\
Desmin & D33 & mm & $1: 100$ \\
$\alpha$ SMA & 1 A4 & $\mathrm{mm}$ & $1: 100$ \\
CD34 & NU-4A1 & $\mathrm{mm}$ & $1: 100$ \\
S-100 protein & & $\mathrm{rp}$ & $1: 500$ \\
Ki-67 & MIB-1 & $\mathrm{mm}$ & $1: 100$ \\
\hline
\end{tabular}

$\mathrm{mm}$ : mouse monoclonal. rm: rabbit monoclonal. rp: rabbit polyclonal.

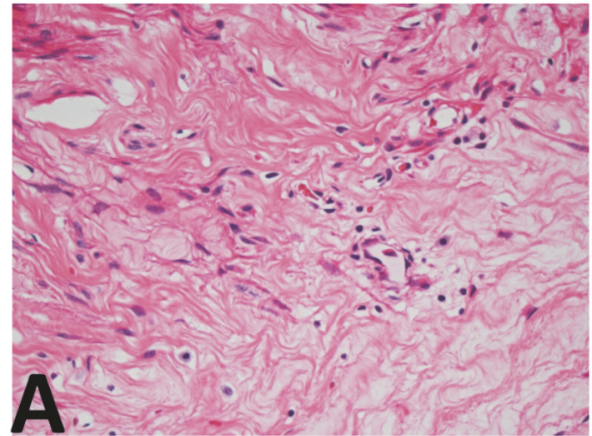

(a)

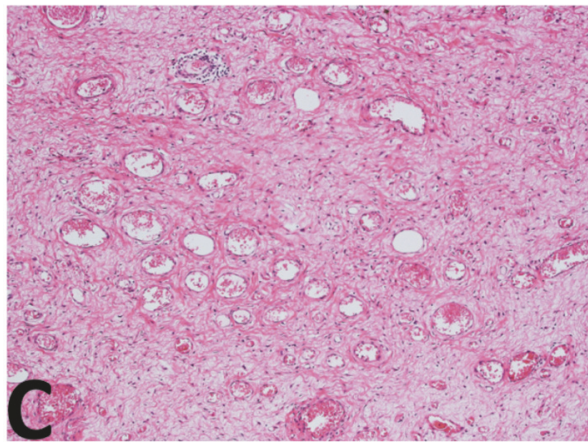

(c)

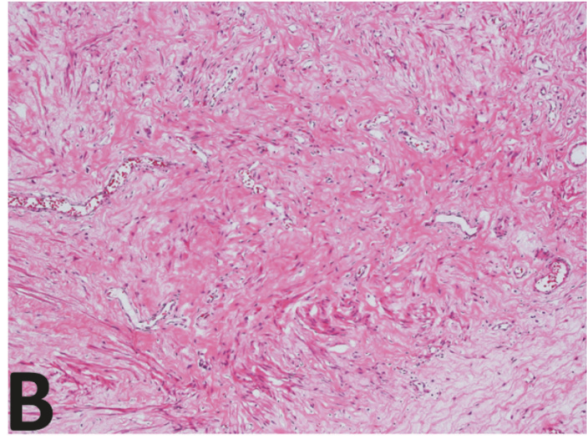

(b)

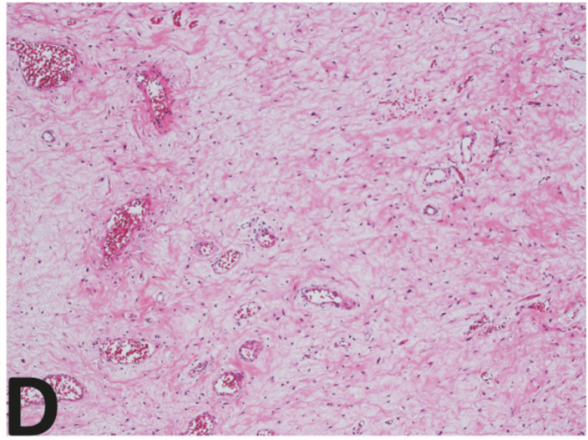

(d)

FIGURE 3: Tumor cells were short and spindle-shaped, arranged in no overt architecture. The nuclei were oval, without prominent atypia. The intervening matrix was edematous and myxoid $((\mathrm{a}) ; \times 400 ; \mathrm{HE})$. In some regions, fine collagen as well as dense collagen was detected $((b) ; \times 100 ; \mathrm{HE})$. The vast majority of blood vessels were small and thin-walled $((\mathrm{c}) ; \times 100 ; \mathrm{HE})$. Some medium-sized blood vessels were also identified within the lesion $((\mathrm{d}) ; \times 100 ; \mathrm{HE})$. There was no specific distribution pattern of the vascularity.

in SMF and some other mesenchymal tumors, is always absent. Immunostaining also provides little help to the discrimination because both SMF and AA, as well as many other mesenchymal tumors in the female genital tract, may show positive for ER, PgR, desmin, alpha-SMA, and CD34 [1-3] (Table 2).

One key point of difference between SMF and AA is the location of the mass. SMF, as its name implies, presents as a mass in the superficial region, whereas AA is characterized by its deep location. Although there is no histological definition of "superficial," based on a radiological report, a location can be termed superficial if it is located in the regions above the muscle [7]. Accordingly, SMF can be described as a mass located above the fascia. Another distinguishing point between SMF and AA is the growth pattern of the tumor. SMF always shows an expansive growth pattern with clear margins, whereas AA shows an aggressive growth pattern and infiltration to the surrounding tissues. Thus, some entrapped tissues, such as neuron fibers, fat tissue, large-size blood vessels, and muscles, can be observed within the AA. Identifying these entrapped tissues is useful in leading to an accurate diagnosis. Because of the infiltrating growth pattern, complete resection is difficult and often results in clinical recurrence. 


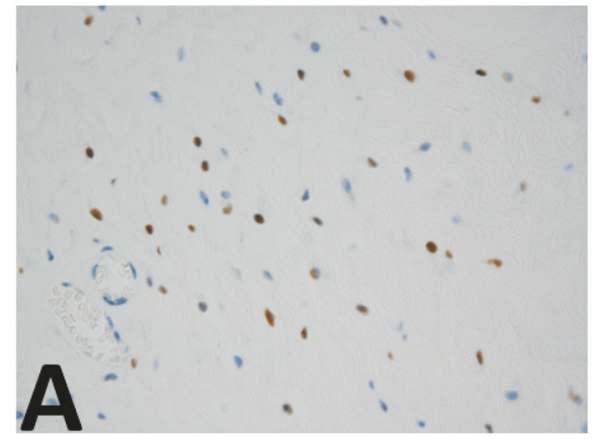

(a)

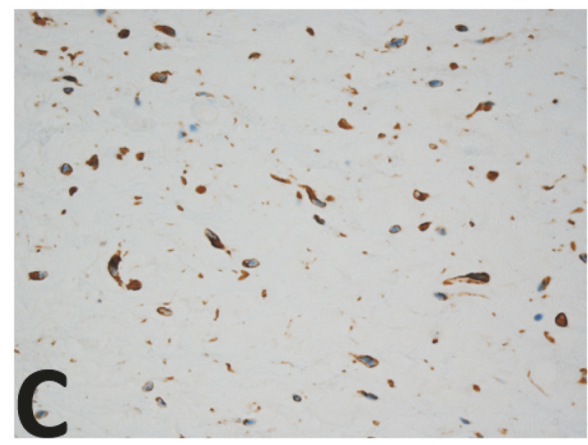

(c)

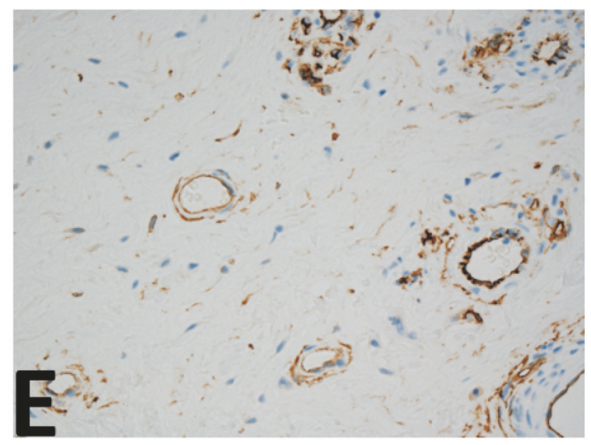

(e)

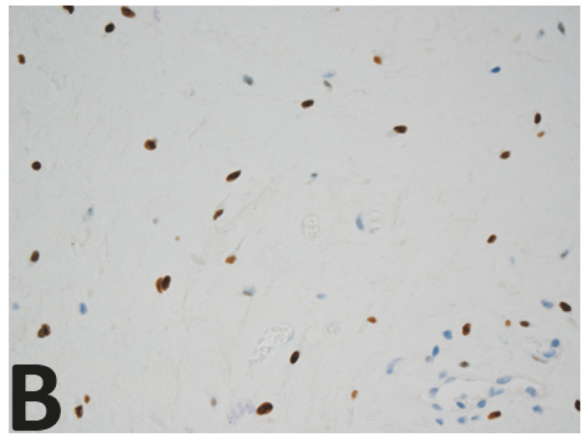

(b)

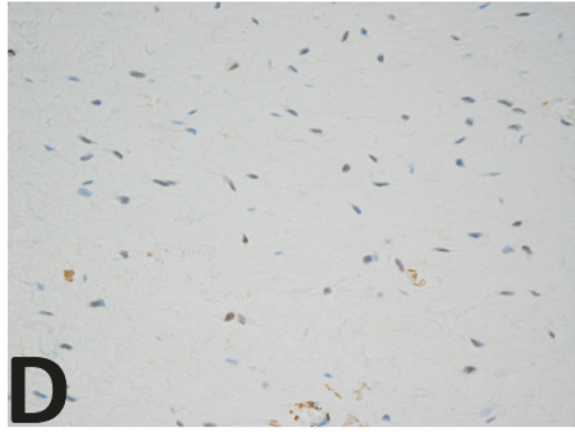

(d)

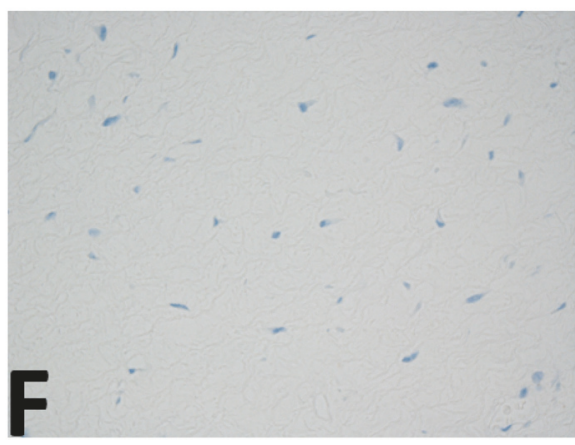

(f)

FIgURE 4: Immunohistochemically, positive nuclear staining for ER (a) and PgR(b) was observed. Tumor cells showed cytoplastic positivity for desmin (c) and $\alpha \mathrm{SMA}(\mathrm{d})$. CD34 (e) and S100 protein were negative in all cells(f).

In addition to AA, other potential mimics of SMF include mammary type myofibroblastoma, angiomyofibroblastoma, and cellular angiofibroma, which all may show similar histological findings with SMF (Table 2). On the other hand, when a tumor shows prominent myxoid changes, a myxoid type dermatofibrosarcoma protuberance should be considered. AMF differs in that the cells usually show an epithelioid appearance, and the cells are often arranged around blood vessels, which we did not identify in our case.

In summary, histologically, SMF may mimic AA by showing massive myxoid and edema changes in some cases. Because SMF and AA have different clinical prognoses, distinguishing SMF from AA is important. Superficial location, sharp borderline from adjacent tissue, expansive growth pattern, and specific vascular pattern may all help to make an accurate diagnosis.

\section{List of Abbreviations}

SMF: Superficial myofibroblastoma

AA: Aggressive angiomyxoma

MRI: Magnetic resonance imaging.

\section{Conflicts of Interest}

There are no conflicts of interest to declare. 
TABLE 2: Pathological features of SMF and other mesenchymal tumors.

(a)

\begin{tabular}{|c|c|}
\hline & Histological features \\
\hline $\begin{array}{l}\text { Superficial myofibroblastoma } \\
\text { (SMF) }\end{array}$ & $\begin{array}{l}\text { Usually moderate, sometimes hypocellularity } \\
\text { Fine and dense collagen in stroma } \\
\text { Small to medium-sized dilated vessels, often centrally located }\end{array}$ \\
\hline Cellular angiofibroma, & $\begin{array}{l}\text { Moderate cellularity } \\
\text { Wispy collagen stroma } \\
\text { Medium-sized vessels, often with hyalinized walls }\end{array}$ \\
\hline $\begin{array}{l}\text { Mammary type } \\
\text { myofibroblastoma, }\end{array}$ & $\begin{array}{l}\text { Moderate to hypercellularity } \\
\text { Thick collagen bundle in stroma, adipose tissues may be present } \\
\text { Blood vessels are not prominent }\end{array}$ \\
\hline $\begin{array}{l}\text { Angiomyofibroblastoma, } \\
\text { (AMF) }\end{array}$ & $\begin{array}{l}\text { Alternating zones of hyper- and hypocellularity. } \\
\text { Loose texture, contains mast cells in stroma, adipose tissues may be } \\
\text { present } \\
\text { Small to medium-sized capillary-like vessels around which } \\
\text { epithelioid stroma cells are clustered }\end{array}$ \\
\hline $\begin{array}{l}\text { Aggressive angiomyxoma } \\
\text { (AA) }\end{array}$ & $\begin{array}{l}\text { Hypocellularity } \\
\text { Myxoid stroma, entrapped tissue may be present } \\
\text { Numerous blood vessels varying from small size to large size with } \\
\text { thick muscular walls }\end{array}$ \\
\hline
\end{tabular}

(b)

\begin{tabular}{lccccc}
\hline & ER & PgR & Desmin & SMA & CD34 \\
\hline $\begin{array}{l}\text { Superficial } \\
\text { myofibroblastoma }\end{array}$ & $\begin{array}{c}80-100 \% \\
(+)\end{array}$ & $\begin{array}{c}80-100 \% \\
(+)\end{array}$ & $\begin{array}{c}75-100 \% \\
(+)\end{array}$ & $\begin{array}{c}0-45 \% \\
(+)\end{array}$ & $\begin{array}{c}55 \% \\
(+)\end{array}$ \\
\hline Cellular angiofibroma & variable expression & variable expression & variable expression & variable expression & variable expression \\
\hline $\begin{array}{l}\text { Mammary-type } \\
\text { myofibroblastoma }\end{array}$ & $\mathrm{ND}$ & $\mathrm{ND}$ & $\begin{array}{c}\text { usually } \\
\text { expressed }\end{array}$ & $\begin{array}{c}\text { variable } \\
\text { expression }\end{array}$ & $\begin{array}{c}\text { usually } \\
\text { expressed }\end{array}$ \\
\hline $\begin{array}{l}\text { Angiomyofibro } \\
\text {-blastoma }\end{array}$ & usually expressed & usually expressed & usually expressed & less common & less common \\
\hline $\begin{array}{l}\text { Aggressive } \\
\text { angiomyxoma }\end{array}$ & $(+)$ & $(+)$ & $(+)$ & variable expression & variable \\
expression
\end{tabular}

\section{Acknowledgments}

This work was supported in part by Grant-in-Aid for Scientific Research (C) from the Japan Society for the Promotion of Science (No. 15K10735 to Wei-Xia Peng).

\section{References}

[1] W. B. Laskin, J. F. Fetsch, and F. A. Tavassoli, "Superficial cervicovaginal myofibroblastoma: Fourteen cases of a distinctive mesenchymal tumor arising from the specialized subepithelial stroma of the lower female genital tract," Human Pathology, vol. 32, no. 7, pp. 715-725, 2001.

[2] R. Ganesan, W. G. McCluggage, L. Hirschowitz, and T. P. Rollason, "Superficial myofibroblastoma of the lower female genital tract: Report of a series including tumours with a vulval location," Histopathology, vol. 46, no. 2, pp. 137-143, 2005.

[3] C. J. R. Stewart, B. Amanuel, B. A. Brennan, S. Jain, R. Rajakaruna, and S. Wallace, "Superficial cervico-vaginal myofibroblastoma: A report of five cases," Pathology, vol. 37, no. 2, pp. 144-148, 2005.

[4] C. D. Olinici, D. Crisan, A. Zolog, and M. Puscas, "Vaginal superficial myofibroblastoma. Case report and review of the literature," Romanian Journal of Morphology and Embryology, vol. 48, pp. 165-170, 2007.

[5] Q. F. Wang, Y. Y. Wu, and J. Wang, "Superficial cervicovaginal myofibroblastoma: report of four cases and literature review," Chinese Medical Journal, vol. 123, pp. 1093-1096, 2010.

[6] G. Magro, R. Caltabiano, D. Kacerovská, G. M. Vecchio, D. Kazakov, and M. Michal, "Vulvovaginal myofibroblastoma: Expanding the morphological and immunohistochemical spectrum. A clinicopathologic study of 10 cases," Human Pathology, vol. 43, no. 2, pp. 243-253, 2012.

[7] F. D. Beaman, M. J. Kransdorf, T. R. Andrews, M. D. Murphey, L. K. Arcara, and J. H. Keeling, "Superficial soft-tissue masses: analysis, diagnosis, and differential considerations," RadioGraphics, vol. 27, no. 2, pp. 509-523, 2007. 


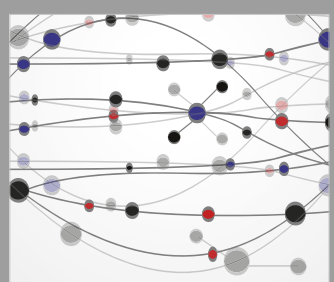

The Scientific World Journal
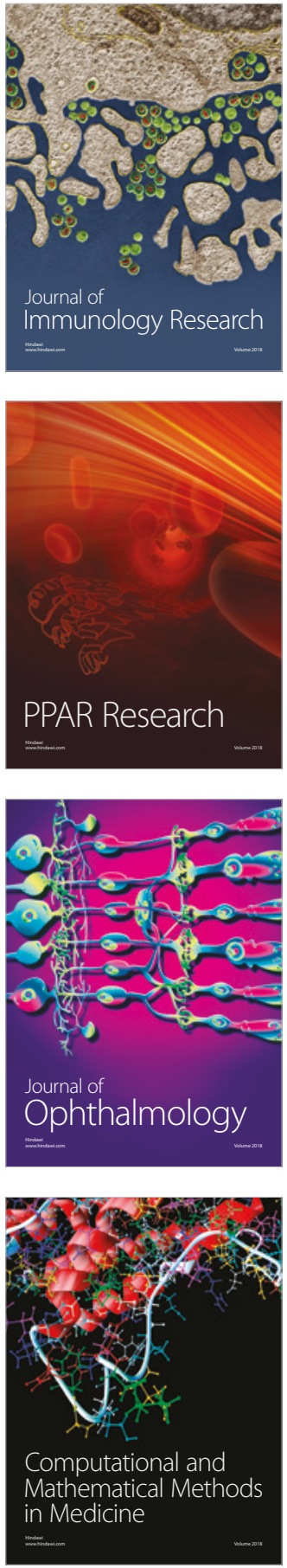

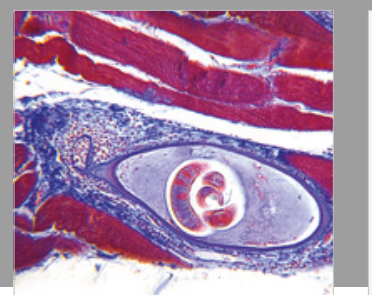

Gastroenterology Research and Practice

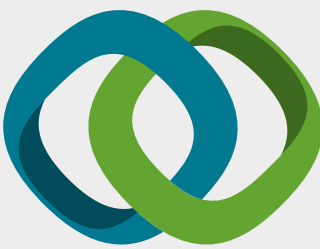

\section{Hindawi}

Submit your manuscripts at

www.hindawi.com
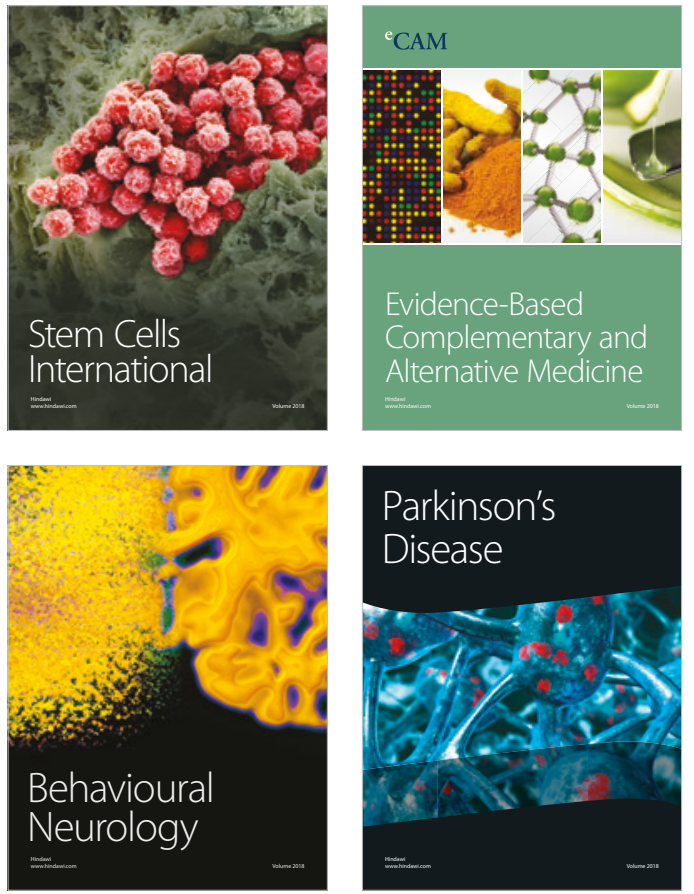

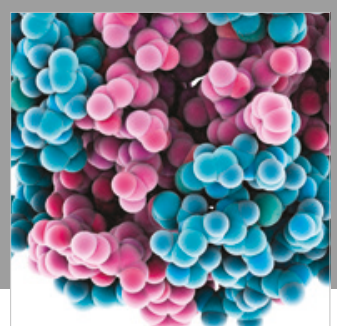

ournal of

Diabetes Research

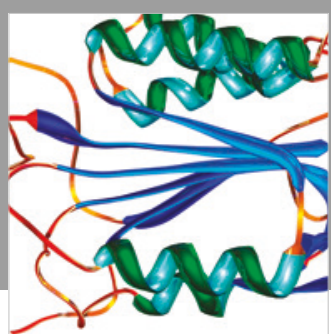

Disease Markers
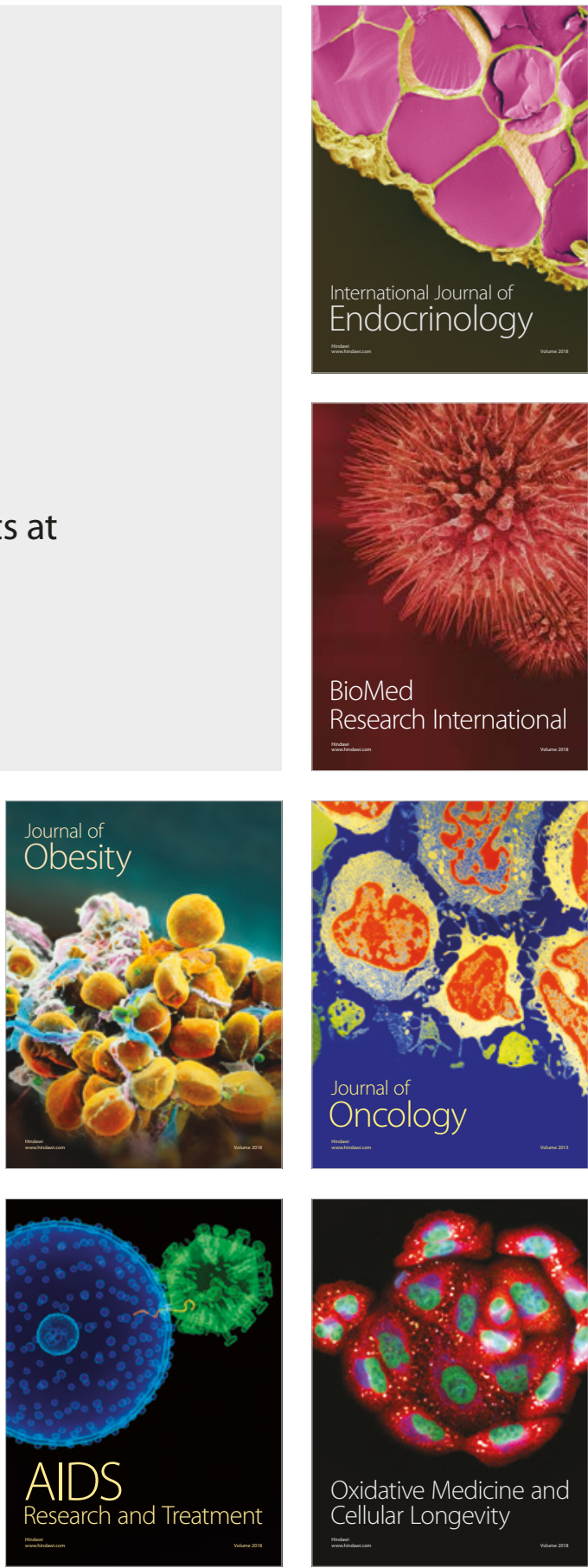